\title{
CHANGES IN HIP MUSCLE STRENGTH AFTER PROXIMAL FEMORAL FRACTURE IN ELDERLY WOMEN
}

\author{
N. Ivanova ${ }^{1}$, H. Aibast $^{1}$, H. Gapeyeva ${ }^{1}$, \\ T. Kums ${ }^{1}$, A. Märtson ${ }^{2}$, M. Pääsuke ${ }^{1}$ \\ ${ }^{1}$ Institute of Exercise Biology and Physiotherapy, \\ University of Tartu, Tartu, Estonia \\ ${ }^{2}$ Department of Traumatology and Orthopaedics, \\ Tartu University Hospital, Tartu, Estonia
}

\begin{abstract}
Hip muscle weakness is an often-occurring condition after displaced fractures of the proximal femur in older patients. The aim of this study was to compare hip muscle strength and pain in elderly female patients after proximal femoral fracture. Nine female patients (mean \pm SD of $71.4 \pm 3.9$ yrs) participated in this study. Knee extensor, hip abductor and adductor muscle strength was evaluated with handheld dynamometer Lafayette (USA) during the first week of postoperative stay in hospital, and 6 months postfracture with fractured and nonfractured leg. Pain was assessed using a visual analogue scale. A week after the operation knee extensor, hip abductor and adductor muscle isometric muscle strength for the fractured leg was decreased $(p<0.05)$ by $50.7 \%, 55.6 \%$ and $38.8 \%$, respectively, compared to the nonfractured limb. At 6-month follow-up, hip muscle strength increased significantly $(\mathrm{p}<0.05)$ in both the fractured and nonfractured leg. Hip muscle strength for the fractured leg was significantly lower $(p<0.05)$ compared with the nonfractured leg 6 months after surgery. Pain score was significantly $(p<0.05)$ higher during the first postoperative week as compared to 6 months follow-up.

It was concluded that voluntary maximal isometric forcegenerating capacity of knee and hip muscles for the fractured leg was markedly increased 1 week and 6 months postoperatively. Isometric
\end{abstract}


force-generating capacity for the fractured leg was significantly improved by 6 months follow-up.

Key words: proximal femoral fracture, hip muscle strength, pain, older patient

\section{INTRODUCTION}

Fractures of the proximal segment of the femur occurring most commonly in elderly patients are a serious medical and socioeconomic problem. Globally there are already more than 1.3 million hip fractures each year. Residual lifetime risk of proximal femoral fractures (PFF) for women and men from 60 age is $44 \%$ and $25 \%$ respectively [17]. Six months after fracture, $30 \%$ of patients die [18], 50\% from survivors need assistance in walking and $90 \%$ need assistance to climb stairs after one year $[4,5]$. Mobility limitations after hip fracture are very common and impaired by deficits of lower-limb muscular strength $[12,15]$. Studies of elderly adults have demonstrated that muscle strength deficit is extremely large after PFF [15, 17]. The measurement of muscle strength is a widely used tehnique in geriatrics [1]. The factors related to the impared muscle function may be trauma, surgical treatment, pain, or disuse of the fractured limb [14]. Hip muscles are important in generating maximal leg extensor power, which correlates closely with mobility in elderly subjects. Structured programmes of high-intensity resistance exercise training can achieve marked improvements in muscle function [3].

The aim of this study was to evaluate hip muscle isometric strength after PFF in elderly women during 1 week and 6 months follow-up.

\section{MATERIAL AND METHODS}

\section{Subjects}

Nine female patients with PFF (mean \pm SD age of $71.4 \pm 3.9 \mathrm{yrs}$, height $1.65 \pm 0.1 \mathrm{~m}$, body mass $69.0 \pm 13.3 \mathrm{~kg}$ and body mass index $25.3 \pm$ $5.2 \mathrm{~kg} / \mathrm{m}^{2}$ ) participated in this study. The subjects were treated by internal fixation in Tartu University Hospital. The fracture types were 31-A1 (1 case, 11.1\%), 31-A2 (2 cases, 22.2\%), 31-A3 (1 case, $11.1 \%), 31-\mathrm{B} 1$ ( 1 case, $11.1 \%), 31-\mathrm{B} 2$ (4 cases, $44.4 \%)$. The type of 
repair devices were: dynamic hip screw -2 cases, proximal femoral nail -2 cases, proximal femoral nail anti-rotation -2 cases, 3 screw fixation -1 case, total hip arthroplasty -2 cases. $55.6 \%$ of the participants had left hip and $44.4 \%$ - right hip fracture. Patients were excluded if they met any of the following criteria: (1) Folstein MiniMental State Examination score less than 25 points; (2) dementia or any other neurodegenerative pathology; (3) any impairment of visual, somatosensory, hearing or vestibular function; (4) inability to walk before fracture. Participants had $30 \mathrm{~min}$. physiotherapy during the first week of hospital stay. The training program included specific exercises for all hip muscle groups to improve mobility, strength, balance and achieve independence in functioning. All participants signed the informed written consent prior to their inclusion in the study. The study carried the approval of the University of Tartu Ethics Committee.

\section{Experimental design}

Isometric strength of leg muscles was measured 1 week and 6 months postfracture with hand-held dynamometer Lafayette (USA), whereas the fractured leg was tested first. During the trials the subjects sat on a chair. For measuring knee extension the tested hip and knee were flexed at $90 \circ^{\circ} \circ$. The dynamometer pad was held by the investigator on distal part of the lower limb. For measuring hip abduction and adduction the hip and knee were flexed at $90 \circ \circ^{\circ}$. The dynamometer pad was held at the lateral and medial femoral condyle respectively. The participants were asked to perform a maximal voluntary isometric contraction. Three trials were performed and the best trial was used for further analysis. Postoperative pain in the hip was evaluated at rest using a visual analogue scale (VAS) at 1 week and 6 months followup. Hip muscle weakness was quantified by comparing maximal voluntary isometric strength outcome between the fractured and nonfractured leg.

\section{Statistical analysis}

Data are mean and standard deviations (SD). The changes in muscle strength and pain at 1 week and 6 months follow-up were assessed by one-way ANOVA. A level of $\mathrm{p} \leq 0.05$ was selected to indicate statistical significance. 


\section{RESULTS}

Knee extensor, hip abductor and hip adductor muscle isometric strength for the fractured leg compared to the nonfractured leg was significantly lower in the first postoperative week (Figure 1). Six months after fracture, hip muscle strength increased significantly in the fractured and nonfractured limbs compared to the first postoperative week. Six months after surgery, isometric knee extensor, hip abductor and adductor muscle strength for the fractured leg was significantly lower compared with the nonfractured leg. Pain score decreased significantly $(\mathrm{p} \leq 0.05) 6$ months after surgery (Figure 2$)$.

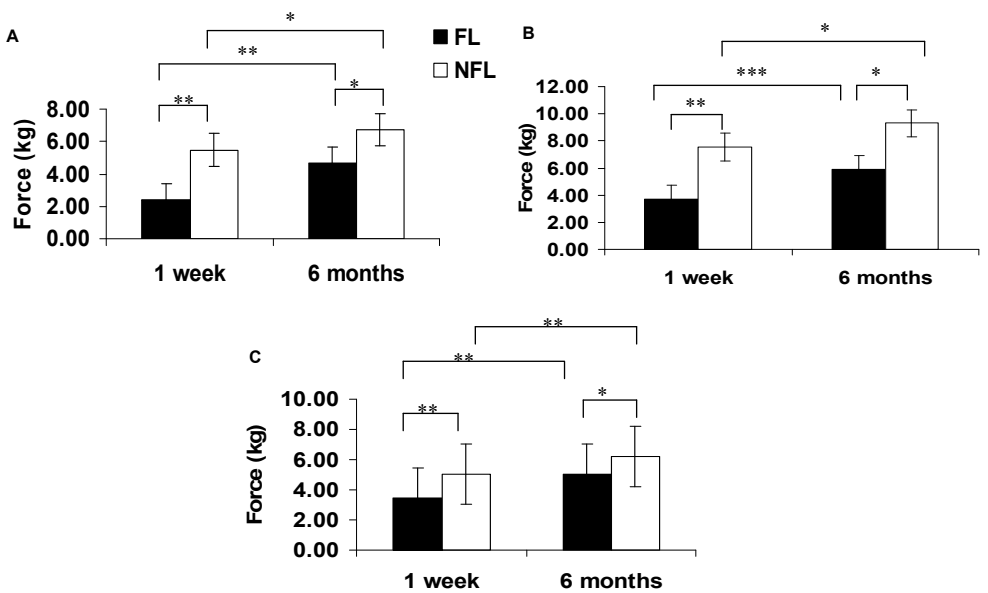

Figure 1. Isometric muscle strength of knee extensors (A), hip abductors (B) and adductors (C) 1 week and 6 months follow-up (mean \pm SD). $\mathrm{FL}=$ fractured leg, $\mathrm{NFL}=$ nonfractured leg $(\operatorname{mean} \pm \mathrm{SE}) .{ }^{*} \mathrm{p} \leq 0.05 ;{ }^{* *} \mathrm{p} \leq 0.01$; $* * * \mathrm{p} \leq 0.001$ 


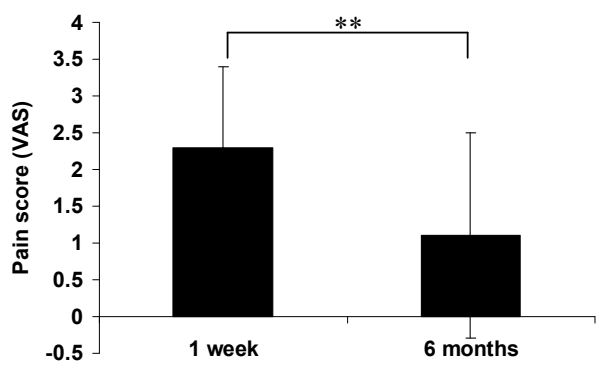

Figure 2. Pain score by VAS scale 1 week and 6 months postfracture (mean $\pm \mathrm{SD}) .{ }^{* *} \mathrm{p} \leq 0.05$.

\section{DISCUSSION}

The first conclusion of our study is that after PFF the hip muscle isometric strength for the fractured leg was significantly decreased 1 week and 6 months postoperatively. In our study muscle weakness was observed in knee extensors, hip abductor and adductor muscles: 1 week following the surgery the muscle strength for the fractured leg was decreased $(\mathrm{p} \leq 0.05)$ by $50.7 \%, 55.6 \%$ and $38.8 \%$ respectively, compared to the nonfractured leg. This is in agreement with the results of several previous studies [4, 15], indicating voluntary maximal isometric hip muscle force-generating capacity after hip fractures in elderly women. Portegijs et al. [15] have shown that hip muscle asymmetrical deficit persisted during the first postoperative week and that at 1 week and 13 weeks after PFF surgery, leg extensor power increased in the fractured leg and the nonfractured leg by $100 \%$ and $30 \%$ respectively, whereas the asymmetrical deficit between the fractured and nonfractured limbs was $28.5 \%$. The reasons of considerable muscle deficit may include a mechanical/anatomical limit, reduced muscle mass (atrophy), postoperative hip pain and edema [4, 13]. In elderly obese patients, diabetes and hypertension can be the reasons of muscle mass loss, which is directly associated with muscle strength loss [1].

The second conclusion is that significant improvement was noted in the strength generating capacity in the fractured leg during 6 months follow-up, but the fractured hip muscle strength deficit compared to the nonfractured leg persisted. Muscle strength 
improvement can be explained by the various strategies to improve mobility, including gait retraining and exercise programs, which were used during the hospital stay and often after discharge from hospital. The aim of the rehabilitation process was to return elderly patients as quickly as possible to their preoperative functional status [9]. The goal of physiotherapy is to improve mobility, strength and achieve independence [11]. In elderly people Host et al. [8] observed a significant difference in the knee extensor strength measurements between the fractured and nonfractured leg 6 months postfracture. Knee extensors were weaker in the fractured limb than in the nonfractured leg, and this difference reached statistical significance $p<0.5$. Our study demonstrated similar results. It has been shown that six months after the fracture, physical exercises have the potential to improve physical outcomes and induce gains in strength so that the fractured limb is essentially equivalent to the nonfractured limb [20]. Studies of postfracture hip have shown that regular exercise (resistive and/or aerobic) can improve physical performance (gait, strength), mobility, walking speed, and quadriceps strength. In a study of a center-based intervention initiated 6 months after a hip fracture, benefits in muscle strength, walking speed, balance, and physical performance were found [13]. Song et al. [18] have shown that after 6-month postoperative period, subjects in the t'ai chi program had significantly greater knee extensor endurance. Despite the effectiveness of the delivery system and the reported improvements in exercise and physical activity [13], the fractured leg can remain by $20 \%$ weaker than the nonfractured leg at 3-36 months after hip fracture [15]. One month after surgery, quadriceps strength decreases to $60 \%$ of the preoperative level [19].

The third conclusion is that at 6 months follow-up the knee extensor, hip abductor and adductor isometric muscle strength deficit for the fractured leg was significant $(\mathrm{p} \leq 0.05): 36.8 . \%, 29.9 \%$ and $19.4 \%$ respectively. It was less than $14.1 \%, 25.7 \%$ and $19.4 \%$, respectively during the first postoperative week. Muscle data demonstrated a slow recovery of muscles. The results of Rasch et al. [16] study show that 6 months postoperatively, hip muscle deficit was $18 \%$ and knee extensors fully recovered after 2 years. Recent studies in elderly people show that between $22 \%$ and $75 \%$ of hip fracture patients do not recover to their prefracture ambulatory or functional status between 6 and 12 months after the fracture [2]. Quadriceps weakness persists even 6 to 13 years after surgery [19]. 
The postoperative and earlier recovery period after surgery is characterized by reduction of muscular loading and has been associated with atrophy of the thigh muscle fibres [6]. Loss of function is expected after PFF [17]. Impared hip muscle function may be an important modifiable contributor. Following PFF there is reduction in fast-twich muscle fibre size in the quadriceps. These fibres are important in generating maximal leg extensor power which correlates closely with mobility in frail elderly subjects after PFF [3].

Pain is one of the factors which may affect functional outcomes during the first postoperative week. Our study demonstrates that the pain score was significantly $(\mathrm{p}<0.05)$ higher during the first week as compared to 6 months follow-up. The few studies of patients with hip fractures have focused on management of perioperative pain symptoms or the relationship between acute postoperative pain and functional outcomes [7]. Portegijs et al. [15] demonstrate that at 1 week after surgical repair of the PFF, $12 \%$ of the participants experienced no pain, $40 \%$ had occasional or slight pain, $23 \%$ had pain on initiation of activity, $14 \%$ had pain with activity, $7 \%$ had constant yet bearable pain, and $5 \%$ had constant unbearable pain. At week 13, $31 \%$ of the women reported no pain, $57 \%$ had occasional or slight pain, and $12 \%$ had pain on initiation of activity.

It has been shown that pain severity with movement during hospitalization for the hip fracture was a significant predictor of functional outcomes 2 months after surgery. I was found that pain during the first 3 postoperative days was associated with longer hospital stays, more postoperative complications, missed or shortened physical therapy sessions, delayed ambulation, and lower locomotion scores at 6 months after fracture repair. These studies suggest that pain in the immediate postoperative period has a significant effect on shortand long-term functional outcomes after hip fracture [7].

In conclusion, voluntary maximal isometric force-generating capacity of knee and hip muscles for the fractured leg was markedly increased 1 week and 6 months postoperatively. Isometric forcegenerating capacity for the fractured leg was significantly improved at 6 months follow-up.

\section{ACKNOWLEDGEMENT}

This study was supported by Estonian Ministry of Education and Research project No SF0180030s07 


\section{REFERENCES}

1. Abizanda P., Navarro J. L., García-Tomás M. I., López-Jiménez E., Martínez-Sánchez E., Paterna G. (2012) Validity and usefulness of hand-held dynamometry for measuring muscle strength in community-dwelling older persons. Arch. Gerontol. Geriatr. 54: 2127

2. Binder E. F., Brown M., Sinacore D. R., Steger-May K., Yarasheski K. E., Schechtman K. B. (2004) Effects of extended outpatient rehabilitation after hip fracture: a randomized controlled trial. JAMA. 292: 837-846

3. Braid V., Barber M., Mitchell S. L., Martin B. J., Granat M., Stott D. J. (2008) Randomised controlled trial of electrical stimulation of the quadriceps after proximal femoral fracture. Aging. Clin. Exp. Res. 20: 62-66

4. Casartelli N. C., Maffiuletti N. A., Item-Glatthorn J. F., Staehli S., Bizzini M., Impellizzeri F. M., Leunig M. (2011) Hip muscle weakness in patients with symptomatic femoroacetabular impingement. Osteoarth. Cartil. 19: 816-821

5. Eastwood E. A., Magaziner J., Wang J., Silberzweig S. B., Hannan E. L., Strauss E., Siu A L. (2002) Patients with hip fracture: subgroups and their outcomes. J. Am. Geriatr. Soc. 50: 1240-1249

6. Gapeyeva H., Buht N., Peterson K., Ereline J., Haviko T., Pääsuke M. (2007) Quadriceps femoris muscle voluntary isometric force production and relaxation characteristics before and 6 months after unilateral total knee arthroplasty in women. Knee Surg. Sports. Traumatol. Arthrosc. 15: 202-211

7. Herrick C., Steger-May K., Sinacore D. R., Brown M., Schechtman K. B., Binder E. F. (2004) Persistent pain in frail older adults after hip fracture repair. J. Am. Geriatr. Soc. 52: 2062-2068

8. Host H. H., Sinacore D. R., Bohnert K. L., Steger-May K., Brown M., Binder E. F. (2007) Training-induced strength and functional adaptations after hip fracture. Phys. Ther. 87: 292-303

9. Lieberman D., Lieberman D. (2002) Rehabilitation after proximal femur fracture surgery in the oldest old. Arch. Phys. Med. Rehabil. 83: $1360-1363$

10. Marottoli R. A., Berkman L. F., Cooney L. M. Jr. (1992) Decline in physical function following hip fracture. J. Am. Geriatr. Soc. 40: $861-866$

11. Mehta S. P., Roy J. S. (2011) Systematic review of home physiotherapy after hip fracture surgery. J. Rehabil. Med. 43: 477-480 
12. Nguyen N. D., Ahlborg H. G., Crnter J. R., Eisman J. A., Ngyyen T. V. (2007) Residual lifetime risks of fractures in women and men. J. Bone. Miner. Res. 22: 781-788

13. Orwig D. L., Hochberg M., Yu-Yahiro J., Resnick B., Hawkes W. G., Shardell M., Hebel J. R., Colvin P., Miller R. R., Golden J., Zimmerman S., Magaziner J. (2011) Delivery and outcomes of a yearlong home exercise program after hip fracture: a randomized controlled trial. Arch. Intern. Med. 171: 323-331

14. Portegijs E., Rantanen T., Kallinen M., Heinonen A., Alen M., Kiviranta I., Sipilä S. (2009) Lower-limb pain, disease, and injury burden as determinants of muscle strength deficit after hip fracture. J. Bone. Joint. Surg. Am. 91: 1720-1728

15. Portegijs E., Sipilä S., Rantanen T., Lamb S. E. (2008) Leg extension power deficit and mobility limitation in women recovering from hip fracture. Am. J. Phys. Med. Rehabil. 87: 363-370

16. Rasch A., Dalén N., Berg H. E. (2010) Muscle strength, gait, and balance in 20 patients with hip osteoarthritis followed for 2 years after THA. Acta. Orthop. 81: 183-188

17. Sherrington C., Tiedemann A., Cameron I. (2011) Physical exercise after hip fracture: an evidence overview. Eur. J. Phys. Rehabil. Med. 47: $297-307$

18. Song R., Roberts B. L., Lee E. O., Lam P., Bae S. C. (2010) A randomized study of the effects of t'ai chi on muscle strength, bone mineral density, and fear of falling in women with osteoarthritis. J. Altern. Comp. Med. 16: 227-233

19. Stevens-Lapsley J. E., Balter J. E., Kohrt W. M., Eckhoff D. G. (2010) Quadriceps and hamstrings muscle dysfunction after total knee arthroplasty. Clin. Orthop. Relat. Res. 468: 2460-2468

20. Sylliaas H., Brovold T., Wyller T. B., Bergland A. (2011) Progressive strength training in older patients after hip fracture: a randomised controlled trial. Age Ageing 40: 221-227

\section{Correspondence to:}

Natalja Ivanova

Institute of Exercise Biology and Physiotherapy

University of Tartu

5 Jakobi Street, 51014 Tartu

Estonia

E-mail: natalja.ivanova@kliinikum.ee 